\title{
EFEITO DE DETERMINANTES DA RENDA DE ESTABELECIMENTOS AGROPECUÁRIOS FAMILIARES DO SUL DO BRASIL: OS RECURSOS E AS CAPACIDADES PERCEBIDAS NO USO DA INFORMAÇÃO
}

Effect of income determinants of family farms in southern Brazil: resources and perceived capacities in information use
Luis Augusto ARAUJO

Empresa de Pesquisa Agropecuária e Extensão Rural de Santa Catarina (EPAGRI)

laraujo@epagri.sc.gov.br

Antonio Marcos FELICIANO

Empresa de Pesquisa Agropecuária e Extensão Rural de Santa Catarina (EPAGRI)

feliciano@epagri.sc.gov.br

Marcia MONDARDO

Empresa de Pesquisa Agropecuária e Extensão Rural de Santa Catarina (EPAGRI) mmondardo@epagri.sc.gov.br

Marcelo Alexandre DE SÁ

Empresa de Pesquisa Agropecuária e Extensão Rural de Santa Catarina (EPAGRI) marcelodesa@epagri.sc.gov.br

\section{RESUMO}

Objetivo: $\mathrm{O}$ artigo analisa os efeitos de determinantes da renda de estabelecimentos agropecuários familiares da região Sul do Brasil, nos anos agrícolas 2014/15, 2015/16, 2016/17 e 2017/18, a partir da disponibilidade de recursos e capacidades percebidas no uso da informação, tendo como referencial teórico a Visão Baseada em Recursos (VBR). Método: A pesquisa assume características de estudo quantitativo, qualitativo, exploratório e descritivo. Uma equação de renda por regressão linear múltipla foi ajustada. Os dados, de uma amostragem intencional, foram obtidos de levantamento contábil, da aplicação de questionário e de grupos focais conduzidos junto aos agricultores. Resultado: Os estabelecimentos agropecuários apresentam variabilidade de renda, que, no limite superior, atinge valores próximos a $R \$$ $90.000,00 /$ unidade de trabalho homem e, no limite inferior, revelam valores próximos a zero em alguns anos. Entre os principais determinantes da renda, os custos reais apresentaram o maior efeito marginal e positivo entre todas as variáveis independentes, superando significativamente às demais variáveis analisadas. Outros determinantes revelaram relação negativa com a renda, como aqueles relacionados ao trabalho familiar e contratado. Em sua face qualitativa, identificouse que os agricultores percebem suas capacidades no uso da informação como fortaleza, obtendo-se sete categorias de análise relacionadas às fontes de informação e seu uso. Conclusões: Os resultados da pesquisa se alinham às ideias da VBR, em que importa o modo como os recursos são combinados para gerar renda (valor) e não, simplesmente, a posse de recursos, e permitiu identificar um gap de conhecimento nessa área a ser suprido por meio de novas pesquisas. PALAVRAS-CHAVE: Renda. Estabelecimento agropecuário. Visão Baseada em Recursos. Informação.

\begin{abstract}
Objective: The article analyzes the effects of income determinants of family farms in southern Brazil, in the 2014/15, 2015/16, 2016/17 and 2017/18 agricultural years, based on the availability of resources and capacities perceived in the use of information, having as theoretical framework the Resource Based View (VBR). Method: The research assumes characteristics of quantitative, qualitative, exploratory and descriptive study. An income equation by multiple linear regression was adjusted. The data, from an intentional sampling, were obtained from accounting survey, questionnaire application and focus groups conducted with farmers. Result: Farming establishments have income variability, which, at the upper limit, reaches values close to $\mathrm{R} \$ 90,000.00$ / man work unit and, at the lower limit, reveal values close to zero in some years. Among the main determinants of income, real costs had the largest marginal and positive effect among all independent variables, significantly exceeding the other variables analyzed. Other determinants revealed a negative relationship with income, such as those related to family and contract work. In its qualitative aspect, it was identified that
\end{abstract}


farmers perceive their capacities in the use of information as a fortress, obtaining seven categories of analysis related to information sources and their use. Conclusions: The research results are aligned with the VBR ideas, in which it matters how resources are combined to generate income (value) and not simply the possession of resources, and allowed to identify a knowledge gap in this area to be supplied through further research.

KEYWORDS: Income. Agricultural establishment. Resource Based View. Information.

\section{Classificação JEL: L25; M21}

Recebido em: 01-08-2019. Aceito em: 17-02-2020. 


\section{INTRODUÇÃO}

No campo da agricultura, os recursos tangíveis ou intangíveis presentes nos estabelecimentos agropecuários poderão ser relevantes se possibilitarem ao agricultor desenvolver e implementar estratégias que gerem um desempenho superior. Assim, uma pergunta merece uma pausa para reflexão: quais recursos são estrategicamente relevantes?

A busca pela resposta encontra suporte no campo de estudo da estratégia, que tem se preocupado em explicar e conduzir as organizações a alcançar vantagens competitivas. As reais fontes de vantagens dos negócios derivam da capacidade de gestão, de consolidar tecnologias no âmbito da organização e das habilidades de produção em competências, possibilitando que se adaptem às oportunidades em transformação (PRAHALAD e HAMEL, 1990). Assim, a capacidade de gestão do agricultor exerce papel destacado na busca das vantagens competitivas e dos ganhos produtivos advindos do conhecimento tecnológico.

Os aspectos comportamentais influenciam o processo decisório, que em sua maioria não é tão racional quanto seria de se esperar, dando origem ao que se chama de viés cognitivo na tomada de decisão (BIRKINSHAW, 2017; KAHNEMAN, 2012). As mudanças que ocorrem na sociedade e nos mercados acabam por influenciar o tipo de comportamento dos agricultores, com consequências psicológicas associadas (MANASSERO et al., 2006). Por isso, considerar as percepções dos agricultores e de como avaliam as suas capacidades no uso da informação pode se constituir um avanço na compreensão da complexidade presente na prática da gestão.

Existem inúmeros trabalhos voltados às empresas urbanas, mas no âmbito do setor agropecuário são incipientes os que se dedicam a investigar as causas de sucesso (ou de fracasso) entre os estabelecimentos agropecuários da Região Sul do Brasil (CARVALHO et al., 2014). Na pretensão de contribuir com o tema, o artigo pode interessar a quem busca conhecer os determinantes da renda, prestar assistência em gestão aos agricultores ou propor ações de políticas públicas adequadas à melhoria de renda para a agricultura familiar.

Não obstante as várias facetas da gestão dos negócios, se busca investigar a interface das relações existentes entre o uso dos recursos, as percepções sobre as capacidades de uso da informação e a renda do estabelecimento. Nessa perspectiva, o artigo analisa os efeitos de determinantes da renda de estabelecimentos agropecuários 
familiares da Região Sul do Brasil, nos anos agrícolas 2014/15, 2015/16, 2016/17 e 2017/18, a partir de recursos e capacidades percebidas no uso da informação, tendo como referencial teórico a Visão Baseada em Recursos (VBR). Tem características de estudo quantitativo e qualitativo, exploratório e descritivo, com amostragem intencional. A partir de levantamento contábil, de aplicação de questionário e da técnica de grupo focal foram empregadas técnicas estatísticas de análise descritiva, de análise de conteúdo e de regressão linear múltipla.

O artigo está estruturado em cinco partes, além dessa introdução. Na primeira, expõem-se o referencial teórico que fundamentou a elaboração do modelo de investigação, a Visão Baseada em Recursos. Na segunda parte, apresenta-se uma revisão bibliográfica sobre a informação como recurso aplicado à agricultura. Na terceira parte, discorrem-se os procedimentos metodológicos adotados na pesquisa. Na quarta parte, descrevem-se as características dos estabelecimentos agropecuários estudados, os resultados das análises de conteúdo e de regressão. Na quinta parte, explicam-se os motivos que levaram aos resultados e suas implicações. Ao final, são apresentadas as conclusões e sugestões para futuros estudos.

\section{VISÃO BASEADA EM RECURSOS (VBR)}

Penrose (1959), em sua obra The Theory of the Growth of the Firm, reconhecidamente forneceu a base intelectual da teoria da Visão Baseada em Recursos (VBR) (WERNERFELT, 1984; SERRA, 2010; MINTZBERG, 2010). Os processos através dos quais as empresas crescem foram expostos e suas ideias estimularam vários estudos e debates no campo da estratégia (RUGMAN; VERBEKE, 2002).

Quanto às possibilidades de crescimento de empresas grandes e pequenas, Penrose argumenta que as empresas grandes não encontram dificuldades de expansão, em função das economias de tamanho e de crescimento. Do contrário, as empresas de menor tamanho apresentam desvantagens competitivas ligadas principalmente às limitações de acesso ao crédito necessário ao financiamento à sua expansão. Para as empresas menores, as oportunidades produtivas tendem a ocorrer em mercados nos quais as empresas maiores não se interessam ou não conseguem ampliar-se na mesma taxa de crescimento da economia (PELAEZ, 2007). 
Penrose buscou oferecer consistência à sua hipótese central de que, independente das condições externas, sempre existem oportunidades de expansão para as empresas, dependendo da capacidade da empresa em identificá-las adequadamente e tirar vantagem delas. A originalidade e a ousadia de seu trabalho residem na importância que atribui aos elementos subjetivos inerentes ao empresário, os quais definem, em última instância, as possibilidades de crescimento da empresa. Assim, ela constrói uma teoria geral do crescimento da firma a partir dos restos, desprezados pela "teoria da firma" (PELAEZ, 2007).

A ideia de recursos contempla os ativos, as capacidades, a informação e o conhecimento geridos por uma empresa e suporta uma classificação em três categorias: (1) recursos físicos - como tecnologia, fábrica, equipamentos, localização geográfica, acesso a matérias-primas; (2) recursos de capital humano - como experiência, capacitação, inteligência, relacionamentos; e, (3) recursos organizacionais - como os processos e as rotinas que coordenam os recursos físicos e humanos da empresa (BALESTRIN; VERSCHOORE, 2016). Assim, os recursos e capacidades são vitais na formulação de estratégia, que deve explorar as especificidades únicas da organização (GRANT, 1991, p.115 apud BARBOSA, 2013, p. 33).

A questão chave da abordagem baseada em recursos para formulação de estratégia consiste em entender as relações entre os recursos, capacidades, competitividade e desempenho e, em particular, os mecanismos pelos quais a vantagem competitiva pode ser sustentada ao longo do tempo. Isso requer o desenho de estratégias que explorem as características únicas de cada empresa. Neste propósito, uma estrutura para análise estratégica deve partir da avaliação dos recursos, da identificação das capacidades da empresa, da avaliação do potencial de geração de renda de recursos e capacidades, da seleção de estratégia para explorar os recursos e capacidades e, por último, na identificação de lacunas de recursos que precisam ser preenchidas (GRANT, 1991).

Vallandro e Trez (2015) apontam cinco oportunidades de pesquisas no campo da administração estratégica, as quais se entende como oportunidades para investigações futuras: 1) as relações entre as diferentes teorias econômicas e a VBR, estratégia e estrutura organizacional; 2) as relações dinâmicas dos recursos; 3) a temática das estratégias de cooperação; 4) a compreensão das estratégias que são empreendidas por empresas que atuam em setores dominados por grandes competidores; e, 5) as pesquisas relacionadas aos investimentos em recursos estratégicos que relacionam VBR, estratégia, estrutura e performance da firma, inspirada no trabalho de Collis e Montgomery (1995). 
Consideram-se, aqui, diferentes oportunidades de pesquisa relacionando a VBR e a agricultura.

Segundo Carvalho et al. (2014), em sua revisão de literatura sobre o uso da VBR em propriedades rurais, a heterogeneidade dos sistemas produtivos rurais revela uma grande possibilidade de investigação do desempenho dos estabelecimentos agropecuários pela VBR. A literatura revisada mostra que os recursos estratégicos para propriedades rurais são os intangíveis, mais presentes nos recursos organizacionais e humanos, confirmando algumas das premissas necessárias para configurar recursos estratégicos, que sejam valiosos, raros e insubstituíveis. Os recursos intangíveis são aqueles que permitem aos agricultores mais efetivamente usufruir dos recursos físicos, tecnológicos e financeiros, promovendo sinergia e maiores ganhos nos seus estabelecimentos agropecuários. Assim, a abordagem da VBR trouxe uma proposta de se olhar para dentro desses estabelecimentos e verificar suas vantagens competitivas a partir de aspectos que são fundamentalmente endógenos.

\section{RECURSOS INFORMACIONAIS NA AGRICULTURA}

A escassez de informação objetiva, ágil e completa desapontava os gestores até pouco tempo. Neste século 21, os gestores devem continuar desapontados também com a informação, mas agora, por outro motivo: a quantidade e o fluxo contínuo disponível. Assim, os gestores precisam ampliar suas capacidades para identificar e analisar as informações críticas à tomada de decisão (KAY et al., 2014). Particularmente para o agricultor, o motivo para ampliar essas capacidades é simples: o futuro de seu estabelecimento agropecuário depende disto.

Os recursos informacionais são considerados os mais difíceis de serem percebidos, por estarem na mente dos indivíduos, nos dados de computadores e nos manuais (NAVES, 2007). A informação é dado investido de relevância e propósito (DRUKER, 2012) podendose traçar alguns paralelos entre informação e conhecimento: o conhecimento diz respeito às crenças e compromissos, ao contrário da informação; o conhecimento é uma função de uma perspectiva, atitude ou intenção, e o conhecimento está relacionado à ação, ao contrário da informação (NONAKA e TAKEUCHI, 1998). Assim, dominar e utilizar as informações no âmbito das organizações é fundamental para se responder as rápidas mudanças das necessidades dos clientes e às novas tendências da sociedade. 
Os agricultores são percebidos pelos demais agentes e elos da cadeia produtiva como gestores de seu estabelecimento agropecuário, e deles são esperadas posturas gerenciais qualificadas, com conhecimentos, habilidades e competências, visando atender determinados mercados com crescentes exigências referentes a padrões, qualidade e inovações nos produtos (BINOTTO et al., 2013). Neste sentido, um dos grandes desafios da gestão é: como lidar eficazmente com as informações e fazer escolhas num contexto de incertezas. Para tanto, é necessário não apenas processar dados e informações, mas criar informações e conhecimentos (NONAKA; TAKEUCHI, 2008). Assim, a própria atuação do agricultor no plano das informações depende fundamentalmente da sua capacidade em processar e lidar com a informação, criando conhecimento.

Pesquisa sobre a criação de conhecimento e a gestão de propriedades rurais do Brasil e Austrália revelou que, onde as pessoas procuram socializar, questionar e inovar constantemente, a possibilidade de transformação de conhecimento tácito ${ }^{1}$ em explícito ${ }^{2}$ é ampliada. Pessoas abertas ao novo e ao questionamento de suas práticas demonstraram apresentar maiores possibilidades de interação para que o conhecimento fosse criado. Embora no contexto que envolve os produtores rurais ocorra compartilhamento de conhecimentos, experiências e informações, é importante que este produza resultados concretos (BINOTTO et al., 2013).

Em estudo conduzido por Moura et al. (2016) foi estudado o uso de ferramentas e informações gerenciais por pecuaristas, buscando identificar os fatores motivadores de seu uso no direcionamento e planejamento dos negócios. Entre os principais resultados evidenciados se destacaram: de um modo geral, os pecuaristas utilizam algumas informações gerenciais informais para a manutenção ou controle de sua produção; possuem limitação em adotar a contabilidade e suas informações formais como ferramenta gerencial e de controle, e que as informações contábeis só são consideradas relevantes quando se tratam de questões referentes ao fisco/imposto de renda.

Os resultados de pesquisa realizada por Zanin et al. (2013), sobre a gestão de propriedades rurais do Oeste de Santa Catarina, evidenciaram que $28 \%$ das propriedades rurais realizaram algum tipo de controle por atividade desenvolvida, $10 \%$ se utilizaram de controle de caixa e $3 \%$ manifestaram o interesse dos filhos em continuarem no

\footnotetext{
${ }^{1}$ Conhecimento presente na experiência, no aprendizado pessoal e profissional. Esse tipo de conhecimento não é facilmente visível e explicável, por ser considerado altamente pessoal e difícil de formalizar, tornando difícil sua comunicação e compartilhamento.

2 Conhecimento materializado em manuais, processos, rotinas, fórmulas científicas. Esse tipo de conhecimento pode ser rapidamente transmitido aos indivíduos, formal e sistematicamente.
} 
desenvolvimento das atividades rurais. Em linhas gerais, o estudo demonstrou, principalmente, a carência da utilização de controles contábeis no meio rural e as fragilidades relacionadas à sucessão familiar.

Com isso, pode se presumir ser a informação um recurso fundamental à gestão do estabelecimento agropecuário, bem como um importante fator de competitividade.

\section{MATERIAL E MÉTODOS}

A presente pesquisa apresenta-se como estudo quantitativo e qualitativo, exploratório e descritivo. Os meios utilizados para a obtenção dos dados foram questionário e técnica de grupo focal e na análise dos dados se empreendeu o método de análise de conteúdo e de regressão linear múltipla. A amostragem foi intencional composta por 237 estabelecimentos agropecuários da Região Sul do Brasil, baseando-se no critério de que eles estivessem contemplados no âmbito do programa "Propriedade sustentável3", parceria estabelecida entre empresas públicas, privada e da sociedade civil.

Figura 1 - Identificação dos municípios polos que indicam a localização dos estabelecimentos agropecuários participantes da pesquisa em Santa Catarina, Paraná e Rio Grande do Sul.

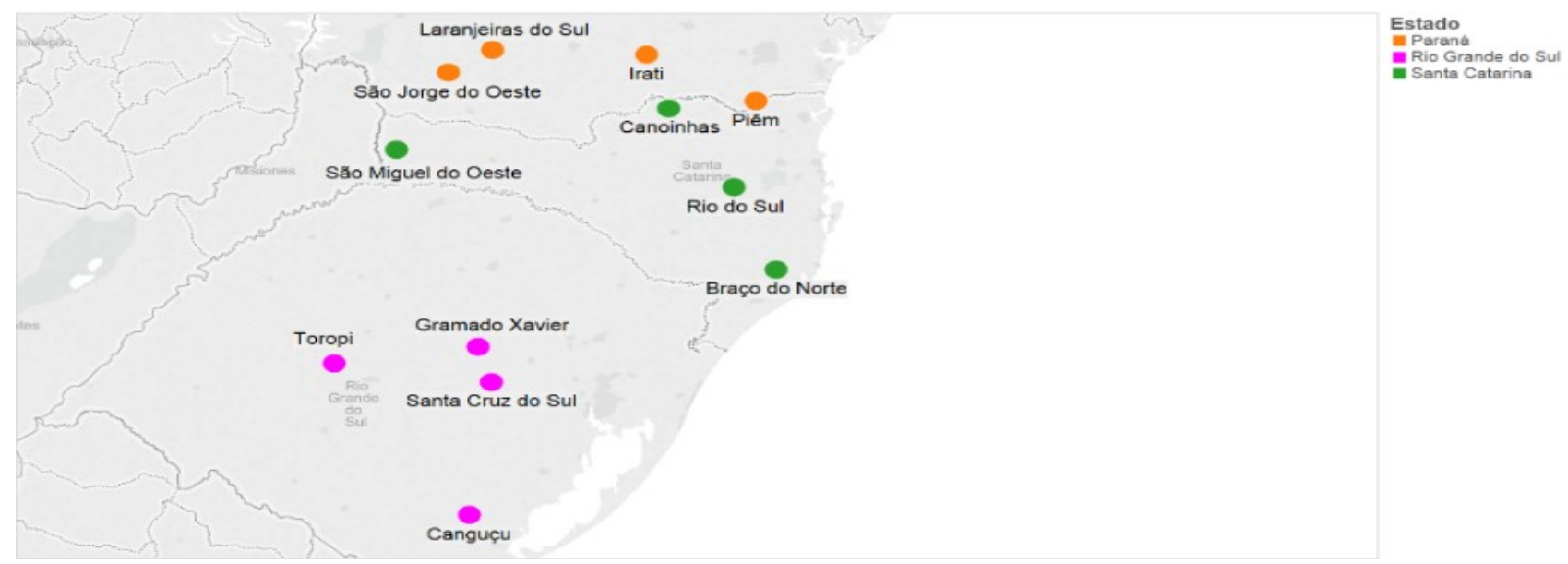

Fonte: Villazon-Montalvan et al. (2017).

3 O programa "Propriedade Sustentável" objetiva apoiar ações de capacitação gerencial e sustentável do agronegócio na pequena propriedade rural. Este programa resulta de um convênio entre a Secretaria de Estado da Agricultura e da Pesca de Santa Catarina, a Empresa de Pesquisa Agropecuária e Extensão Rural de Santa Catarina, a Souza Cruz e as Federações dos Trabalhadores na Agricultura dos estados de Santa Catarina, Paraná e Rio Grande no Sul. 


\subsection{Coleta dos Dados Primários}

Os dados primários foram coletados por meio da aplicação de questionário, visando obter a percepção sobre um conjunto de variáveis, e pela utilização do método de grupo focal ao conjunto de agricultores. Na aplicação do questionário, cada variável relacionada à gestão da informação foi classificada pelos agricultores como fortaleza ou fraqueza, por serem relativas ao ambiente interno. Em seguida, solicitou-se a manifestação do entrevistado quanto a importância da variável nas práticas de gestão: (a) Sem importância; (b) Pouco importante; (c) Importante; (d) Muito importante. As respostas a cada variável foram ponderadas, atribuindo-as valores de 0 a 3, nessa ordem, de acordo com o grau de importância. $\mathrm{Na}$ apresentação dos resultados, dado o total de questionários e os critérios estabelecidos de ponderação, o grau de importância máximo que poderia ser obtido em cada variável foi 711 pontos (237 agricultores que responderam o questionário atribuindo importância 3).

Foram realizadas doze reuniões para aplicação do grupo focal, sendo 4 no Rio Grande do Sul, 4 em Santa Catarina e 4 no Paraná. Cada grupo focal contou com um moderador, que procurou não divergir dos temas previamente definidos, sob a forma de perguntas abertas relacionadas ao uso da informação, entre outras perguntas.

No início da aplicação do grupo focal foram pactuadas regras, assim definidas: as perguntas deveriam ser respondidas individualmente; o respondente identificava-se pelo nome; o respondente que não tivesse opinião formada sobre a pergunta deveria manifestarse dessa forma, e, a qualquer momento, os respondentes poderiam solicitar maiores explicações sobre as perguntas.

\subsection{Análise dos Dados}

A análise de conteúdo foi usado para compor os resultados do método de grupo focal, consistindo no desmembramento do texto em categorias agrupadas e compreendeu três fases: (1) pré-análise - seleção do material transcrito dos 12 grupos focais (contendo o posicionamento dos 237 agricultores sobre as questões) e leitura flutuante; (2) exploração do material - realizada através do recorte de texto das narrativas dos agricultores comparáveis e o estabelecimento de categorias temáticas, e, por último (3) interpretação e inferências respaldadas no referencial teórico, ressaltando os aspectos considerados 
semelhantes e diferentes no entendimento dos agricultores sobre as variáveis relacionadas à gestão da informação (SILVA, 2012; BARDIN, 2011).

Para o cálculo dos índices das variáveis qualitativas referentes às percepções dos agricultores, foi calculado um indicador para cada variável de cada observação, adaptado de Araújo et al. (2017). O espectro de variação do grau de importância varia de zero (0), situação de percepção de fraqueza avaliada como de muita importância, a sete (7), situação de percepção de fortaleza avaliada como de muita importância, de acordo com o ranqueamento representado na Figura 2.

Figura 2 - Pontuação de cada resposta possível das variáveis percebidas pelos agricultores, reorganizados para a realização do teste de correlação com a renda.

\begin{tabular}{|c|c|c|c|c|c|c|c|}
\hline 0 & 1 & 2 & 3 & 4 & 5 & 6 & 7 \\
\hline \multirow[t]{2}{*}{$\begin{array}{c}\text { Muito } \\
\text { importante }\end{array}$} & Importante & $\begin{array}{c}\text { Pouco } \\
\text { importante }\end{array}$ & $\begin{array}{c}\text { Sem } \\
\text { importância }\end{array}$ & $\begin{array}{c}\text { Sem } \\
\text { importância }\end{array}$ & $\begin{array}{c}\text { Pouco } \\
\text { importante }\end{array}$ & Importante & $\begin{array}{c}\text { Muito } \\
\text { importante }\end{array}$ \\
\hline & Frac & eza & & & For & leza & \\
\hline
\end{tabular}

Fonte: Adaptado de Araújo et al. (2017).

O modelo utilizado para o cálculo da Renda da operação agrícola por Unidade de trabalho homem (Y) foi do tipo:

$$
\ln Y_{j}=\alpha+\sum \beta_{i} X_{i j}+u_{j}
$$

onde $\alpha$ e $\beta_{i}$ são parâmetros e $u_{j}$ são os erros aleatórios obedecendo às pressuposições usuais. O ajustamento foi feito por mínimos quadrados ordinários.

A variável dependente $(Y)$ é o logaritmo neperiano da Renda da operação agrícola ${ }^{4}$ por Unidade de trabalho homem ${ }^{5}$ (Roa/Uth) obtido pelos estabelecimentos agropecuários pesquisados, sendo que o uso da função logarítmica se justifica pela forte assimetria da distribuição da renda. Além disso, a escolha da Renda da operação agrícola como equivalente aos lucros de longo prazo dos estabelecimentos, ocorreu por se considerar o quantum da Renda da operação agrícola um bom indicador de desempenho do estabelecimento agropecuário, especialmente na ótica dos agricultores.

\footnotetext{
${ }^{4}$ A Renda da operação agrícola (Roa) é a diferença entre a renda bruta e os custos reais, que são todos os custos do estabelecimento agropecuário, incluindo a depreciação (com exceção da remuneração da mão-deobra familiar e dos juros sobre o capital próprio). É importante registrar que os custos de oportunidade são um custo calculado e, portanto, não compõe os custos reais (ARAÚJO, 2009).

5 Uma Unidade de trabalho homem (Uth) corresponde a um adulto que trabalha 8 horas por dia, durante 300 dias por ano. Equivale ao aporte de trabalho de uma pessoa adulta em tempo integral, no estabelecimento agropecuário, durante um ano (ARAÚJO, 2009).
} 
São consideradas as seguintes variáveis explanatórias, que foram agrupadas em três categorias:

— Recursos físicos e financeiros: Superfície agrícola útil (Sau); Unidade de trabalho homem familiar (Uth familiar); Unidade de trabalho homem assalariada (Uth assalariada); e, Logaritmo dos Custos reais/Uth (Ln_Custos reais), onde o coeficiente dessa variável corresponde a elasticidade da Roa/Uth em relação aos custos reais;

- Recursos de capital humano e tecnológicos: Idade do principal gestor do estabelecimento agropecuário (Idade); Grau de instrução do principal gestor (Grau de instrução); Rendimento da atividade tabaco estufa (Tabaco estufa (kg/ha); e, Logaritmo do capital máquinas e equipamentos/Uth (Ln_Capital máquinas).

- Percepções sobre as competências em lidar com a informação: Distribuição de tempo do responsável principal; Uso do computador para a gestão; Acesso a informações por meio de técnicos de ATER; Uso do fluxo de caixa; Uso de sistema de contabilidade eletrônica; e, Disponibilidade de meios de comunicação.

Além disso, considerou-se o uso das seguintes variáveis explanatórias:

- Duas variáveis binárias para distinguir os Estados da Região Sul: Rio Grande do Sul (tomado como base), Santa Catarina (UF_SC) e Paraná (UF_PR).

- Um variável ano (Ano) que considera todos os anos juntos.

Os dados foram analisados utilizando-se o SAS(C) Analytics 9.4. De acordo com Kageyama e Hoffmann (2000, p. 13), neste modelo os coeficientes de regressão medem a mudança relativa (ou proporcional) na renda, dada uma variação absoluta nas variáveis explicativas (Xi). Assim, para uma estimativa b de um coeficiente, 100[eb-1] dará a variação percentual esperada em $Y$, dada uma variação de 1 unidade em $X$, descontados os efeitos das demais variáveis explanatórias incluídas no modelo. De outra forma, se X é uma variável binária, obtém-se a diferença percentual entre o valor esperado de $Y$ na categoria tomada como base e o valor da categoria para a qual a variável binária assume valor 1 .

\subsection{Hipóteses}

Com base no modelo conceitual e na revisão da literatura, foram elaboradas as hipóteses:

- H1: quanto maior o nível de recursos físicos e financeiros, maior é a renda; 
- H2: quanto maior o nível de recursos de capital humano e tecnológicos, maior é a renda;

- H3: quanto maior a avaliação positiva sobre as competências em lidar com a informação, maior a renda.

Assim, os recursos e as capacidades percebidas sobre o uso da informação serão testados a sua associação à renda dos agricultores.

\section{RESULTADOS}

$\mathrm{Na}$ primeira seção, descrevem-se as características dos estabelecimentos agropecuários e do perfil socioeconômico do agricultor e sua família. Na segunda seção, apresentam-se os dados referentes às capacidades percebidas em usar a informação e a importância atribuída pelos agricultores. Por último, revelam-se os recursos e capacidades percebidas no uso da informação determinantes da renda dos estabelecimentos agropecuários.

\subsection{Caracterização dos Estabelecimentos Agropecuários e Perfil Socioeconômico}

A Figura 3 apresenta a renda de estabelecimentos agropecuários do Sul do Brasil durante os anos agrícolas 2014/15, 2015/16, 2016/17 e 2017/18. É interessante observar a ocorrência de distintos valores de renda dos estabelecimentos agropecuários, independentemente do ano agrícola considerado.

A renda média dos estabelecimentos agropecuários do Sul do Brasil encontra-se relativamente próxima, por ano agrícola, em torno de $\mathrm{R} \$ 28.946,00$. No entanto, um desvio padrão médio de $\pm \mathrm{R} \$ 15.462,00$ revela a variabilidade de renda dentro do mesmo ano agrícola. Admitindo-se uma distribuição normal em torno da média de $\mathrm{R} \$ 28.946,00$ $\pm 15.462,00,68 \%$ dos estabelecimentos possuem renda dentro desse intervalo. Isto significa que $32 \%$ do total dos estabelecimentos possuem renda acima de $R \$ 44.408,00$ e renda abaixo de $\mathrm{R} \$ 13.484,00$ por pessoa. 
Figura 3 - Desempenho da renda de estabelecimentos agropecuários do Sul do Brasil, entre os anos agrícolas 2014/15 e 2017/18
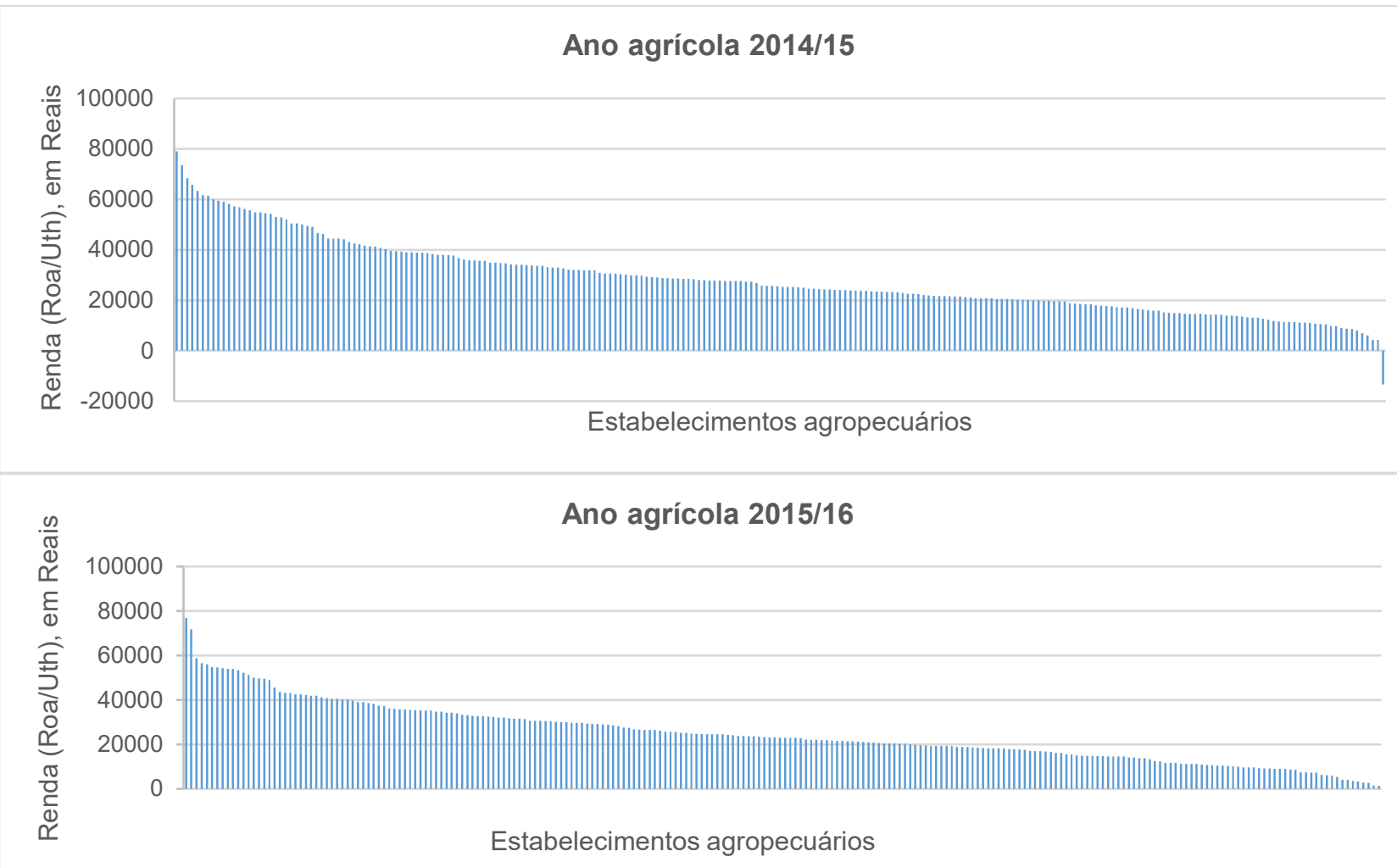

Ano agrícola 2016/17
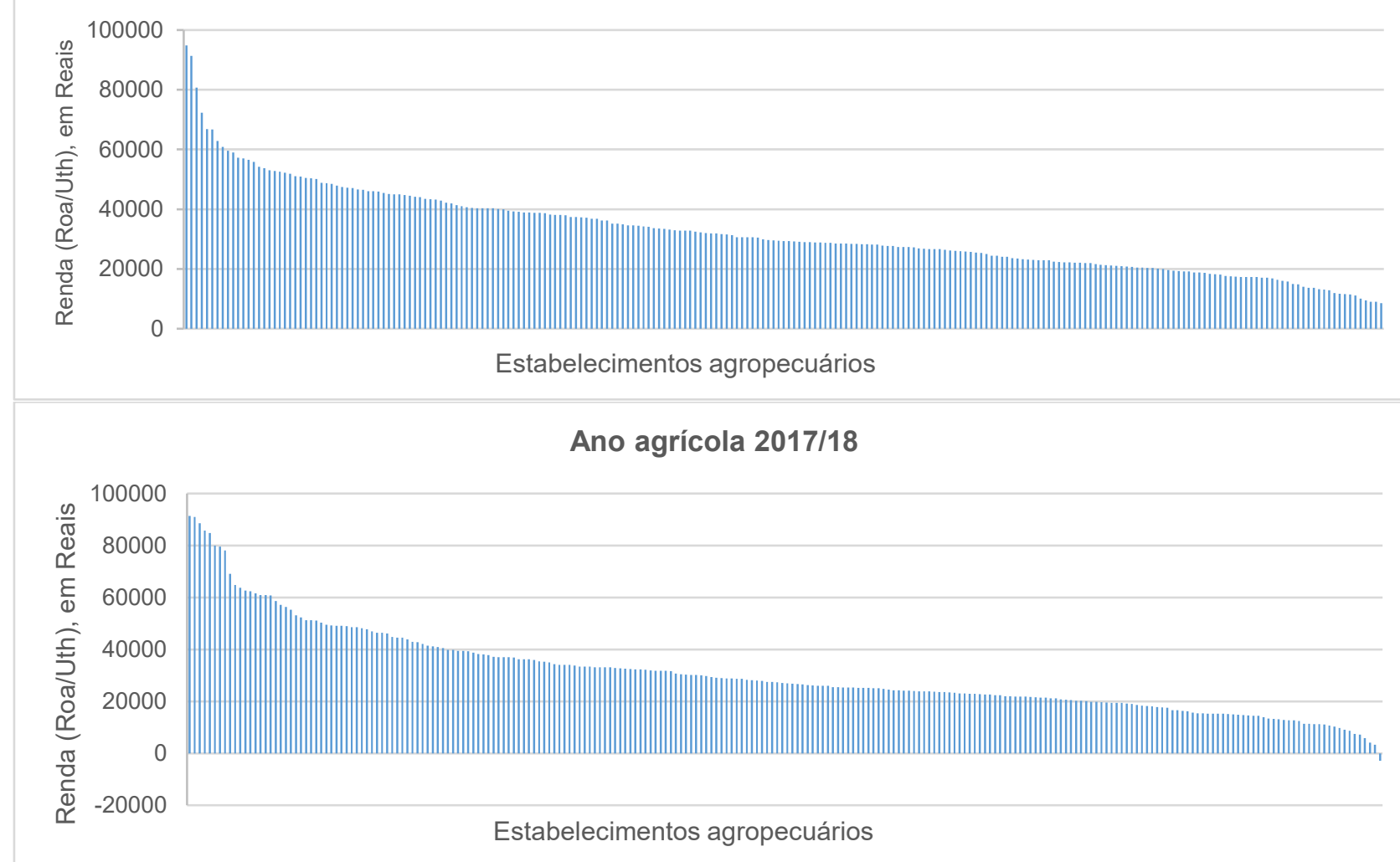

Fonte: Elaboração dos autores (2019), com base nos dados obtidos do Contagri@, com valores em Reais atualizados pelo IGP_di de junho de 2018. 
Os dados da renda dos estabelecimentos agropecuários foram organizados em ordem decrescente, para cada ano agrícola. Assim, tomando-se como exemplo os dados para o ano agrícola 2014/15, os pontos localizados mais à esquerda representam valores de renda próximos a $\mathrm{R} \$ 80.000,00 /$ th, enquanto que mais à direita representam uma renda negativa (-) $\mathrm{R} \$ 13.434,00 / U$ th. Essas diferenças de desempenho de renda (desigualdades) se mantêm entre os anos agrícolas, com ligeiras alterações dentro de cada ano agrícola. Além disso, observa-se que, nos dois últimos anos agrícolas, alguns estabelecimentos do Sul do Brasil chegaram a obter renda acima de $\mathrm{R} \$ 90.000,00 /$ th.

A Tabela 1 apresenta a média e desvio padrão dos recursos físicos disponíveis e do rendimento das principais atividades dos estabelecimentos agropecuários.

Tabela 1 - Média e desvio padrão da presença de recursos e de rendimento das principais atividades agropecuárias, por ano agrícola

\begin{tabular}{|c|c|c|c|c|c|c|c|c|c|}
\hline & \multicolumn{2}{|c|}{ Ano $2014 / 15$} & \multicolumn{2}{|c|}{ Ano $2015 / 16$} & \multicolumn{2}{|c|}{ Ano $2016 / 17$} & \multicolumn{2}{|c|}{ Ano $2017 / 18$} & \multirow{2}{*}{$\frac{\mathrm{N}^{*}}{\text { Total }}$} \\
\hline & Média & DP & Média & DP & Média & $\mathrm{DP}$ & Média & DP & \\
\hline Custos reais & 22.015 & \pm 13.446 & 22.989 & \pm 13.970 & 23.855 & \pm 16.466 & 25.225 & \pm 16.961 & 923 \\
\hline \multicolumn{10}{|l|}{ Área e trabalho } \\
\hline Área explorada (em & 13,5 & $\pm 8,5$ & 14,4 & $\pm 9,9$ & 15,1 & $\pm 11,1$ & 14,6 & $\pm 10,9$ & 923 \\
\hline Área $\mathrm{t}$ & 18,8 & $\pm 11,3$ & 19,3 & $\pm 12,4$ & 20,1 & $\pm 13,4$ & 19,7 & $\pm 13,2$ & 923 \\
\hline Uth fa & 2,5 & $\pm 1,0$ & 2,5 & $\pm 0,9$ & 2,5 & $\pm 0,9$ & 2,5 & $\pm 0,9$ & 923 \\
\hline Uth assalariada & 0,3 & $\pm 0,3$ & 0,2 & $\pm 0,2$ & 0,3 & $\pm 0,2$ & 0,3 & $\pm 0,4$ & 563 \\
\hline \multicolumn{10}{|l|}{ Capital (em mil Reais/Uth) } \\
\hline - Total & 187,49 & $\pm 144,42$ & 186,8 & $\pm 132,28$ & 163,48 & $\pm 105,26$ & 195,11 & \pm 149.51 & 923 \\
\hline - Máquinas e $\epsilon$ & 33,75 & $\pm 30,18$ & 34,68 & $\pm 31,06$ & 30,46 & $\pm 26,30$ & 40,46 & \pm 34.9 & 923 \\
\hline \multicolumn{10}{|l|}{ Rendimento } \\
\hline Tabaco estufa & 2.975 & \pm 622 & 2.195 & \pm 567 & 2.876 & \pm 781 & 2.881 & \pm 595 & 625 \\
\hline Tabaco galpão (kg/ha) & 2.232 & \pm 601 & 1.837 & \pm 513 & 2.692 & \pm 488 & 2.301 & \pm 567 & 288 \\
\hline Milho s & 94 & \pm 47 & 76 & \pm 36 & 117 & \pm 79 & 92 & \pm 85 & 498 \\
\hline Soja safra (sc60/ha) & 51 & \pm 13 & 50 & \pm 17 & 64 & \pm 19 & 58 & \pm 16 & 218 \\
\hline Cebola (kg/ha) & 21.106 & \pm 7.721 & 11.798 & \pm 5.817 & 23.584 & \pm 6.618 & 15.894 & \pm 7.252 & 34 \\
\hline Bovino de leite (litros/SFP) & 8.384 & \pm 6.457 & 8.609 & \pm 6.948 & 8.985 & \pm 8.555 & 11.468 & \pm 11.034 & 199 \\
\hline
\end{tabular}

Fonte: Elaboração dos autores (2019), com base nos dados obtidos do Contagri@. *Número de observações nos quatro anos.

A média dos recursos físicos e do rendimento das principais atividades agropecuárias para os quatro anos podem ser assim descritos: em relação à dimensão da exploração, os estabelecimentos possuem área total de 19,4ha \pm 12,6 e uma superfície agrícola útil (área explorada) de 14,4ha $\pm 10,1$ ha, com pequenas diferenças de média entre os estados; no tocante à dimensão de trabalho, contam com 2,5Uth familiar $\pm 0,9 \mathrm{e}$ contratam 0,25 Uth assalariada $\pm 0,29$; em relação à dimensão do capital da exploração 
agropecuária empregam um total de $R \$ 183.279,00 /$ th $\pm 134.369,00$, sendo que o capital máquinas e equipamentos corresponde a $\mathrm{R} \$ 34.848,00 \pm 30.938,00$.

Os rendimentos médios das atividades agrícolas e seu desvio padrão exibem um determinado padrão de ocorrência, apesar das influências do ano agrícola. Observe-se que as atividades milho safra (95sc de 60kg por hectare \pm 66 ) e bovinocultura de leite (9.303 litros de leite por hectare de pasto \pm 8.373), além de revelar alterações no rendimento médio nos anos considerados, exibiu um desvio padrão mais alto relativamente às demais atividades agropecuárias (DP de $70 \%$ em relação à média de rendimento do milho safra e 90\% para bovinocultura de leite). Em contrapartida, a atividade tabaco estufa obteve 2.736 $\mathrm{kg} / \mathrm{ha} \pm 715$, apresentando um desvio padrão médio comparativamente mais baixo (26\% em relação à média do Tabaco estufa).

Considerando-se o número total de observações (N=923) nos quatro anos agrícolas, $68 \%$ dos estabelecimentos agropecuários pesquisados cultivam tabaco estufa, 54\% milho safra, $31 \%$ tabaco galpão, $24 \%$ soja safra e $22 \%$ bovino leite. Dependendo da região ou estado da federação, outras atividades aparecem com alguma frequência, como a bovinocultura mista e de corte e a cebolicultura, esta última desenvolvida no Alto Vale do Itajaí, SC.

A descrição do perfil socioeconômico do agricultor e sua família tem por base os dados resultantes de questionário aplicado em 2016. Naquele ano, entre os 875 membros das famílias participantes da pesquisa, 471 eram do sexo masculino (53,8\% do total), 398 do sexo feminino $(45,5 \%)$ e 6 não responderam $(0,7 \%)$. Na estrutura etária dos membros das famílias dos estabelecimentos agropecuários há o predomínio de pessoas adultas entre 26 e 60 anos (56,2\% do total). A faixa etária mais jovem, até 25 anos, contemplava 36,8\% do total, enquanto as pessoas com mais de 60 anos representavam 6,2 \% do total.

Em termos de grau de instrução dos membros das famílias dos estabelecimentos agropecuários, a categoria "ensino fundamental incompleto" revela a maior presença, com $53,8 \%$ do total dos membros das famílias, a categoria de "ensino médio completo" apareceu em segundo lugar, com 18,8\%, seguida da categoria "ensino fundamental completo" ( $1^{\circ}$ ao $9^{\circ}$ ano) com $11,3 \%$. Apenas 13 pessoas, $1,5 \%$ do total, declararam possuir ensino superior completo.

Em relação ao tipo de atividade exercida, 58,2\% do total de membros das famílias declararam dedicação exclusiva em atividades agropecuárias, 11,6\% dedicação parcial e $3,5 \%$ dedicação exclusiva em atividades não agropecuárias. Além disso, 17,2\% eram estudantes, $3,8 \%$ aposentados e $5,8 \%$ enquadravam-se em outras situações. Por último, 
em relação à disponibilidade de computador, $94,1 \%$ dos estabelecimentos agropecuários possuíam um ou mais computadores na sua unidade. Entre os entrevistados, $21,5 \%$ admitiram possuir dois ou mais computadores no seu estabelecimento, sendo que do total de membros das famílias (875), 47,6\% admitiram utilizar a internet.

\subsection{Capacidades Percebidas em Usar a Informação}

A Figura 4 apresenta o grau de importância atribuído pelos agricultores às variáveis relacionadas às capacidades percebidas no uso da informação e de sua avaliação em termos de fortalezas ou de fraquezas, tendo-se por base os resultados da aplicação de questionário.

Figura 4 - Percepção de fortaleza ou fraqueza e grau de importância atribuído as variáveis relacionadas a capacidade de uso da informação, pelos agricultores da Região Sul do Brasil

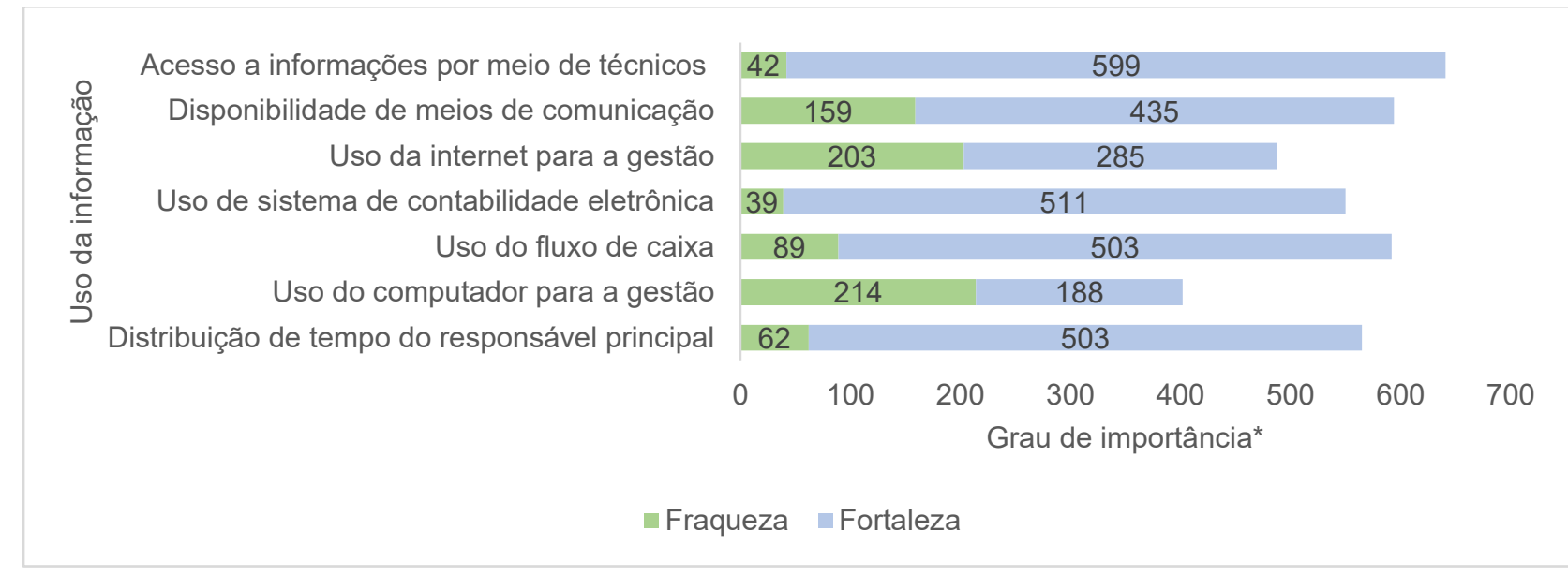

Fonte: Elaborado pelos autores.

*Grau de importância - O gráfico foi elaborado a partir da somatória das pontuações das variáveis relacionadas ao uso da informação. Cada variável foi respondida por 237 agricultores e às mesmas foi atribuído peso de 0 a 3, podendo se obter pontuação máxima de 711 .

Os agricultores percebem suas capacidades no uso da informação como fortaleza, em $78 \%$ do grau de importância total atribuído. Entre as variáveis dessa dimensão, os agricultores perceberam destacadamente como pontos fortes a "Informações e conhecimentos por meio de técnicos" $(93,4 \%)$ e "Uso de sistema de contabilidade eletrônica" (92,9\%). Em outro sentido, as variáveis mais percebidas como fraqueza foram o "Uso do computador para a gestão" (53,2\%), o "Uso da internet para a gestão" (41,6\%), a "Disponibilidade de meios de comunicação" $(30,8 \%)$. Convém destacar que os 
agricultores participantes possuem controle contábil das atividades relativas aos seus negócios por meio do uso, por parte de técnicos, de um sistema de contabilidade eletrônica. Portanto, percebem-no como uma fortaleza, por recebem periodicamente os resultados contábeis dos seus negócios.

Com o objetivo de aprofundar as percepções dos agricultores sobre os assuntos supracitados, foram aplicadas sessões de grupo focal, visando identificar as fontes de informação, as facilidades e dificuldades de acesso e uso da informação e os relacionamentos informacionais, que estabelecem no momento da tomada de decisão. 0 Quadro 1 apresenta as principais manifestações identificadas a partir dos dados coletados das sessões de grupo focal, sintetizadas em categorias de análise.

Quadro 1 - Categorias de análise relacionadas às fontes de informação e seu uso

\begin{tabular}{|c|c|}
\hline Categorias Intermediárias & Categorias iniciais \\
\hline i. $\quad$ Canais de Informação - Mídias & $\begin{array}{l}\text { Televisão } \\
\text { Rádio } \\
\text { Internet }\end{array}$ \\
\hline i.Assistência Técnica & $\begin{array}{l}\text { Assistência técnica pública } \\
\text { Assistência técnica privada }\end{array}$ \\
\hline Capacitação & $\begin{array}{l}\text { Cursos } \\
\text { Dias de campo } \\
\text { Visita a propriedades } \\
\text { Reuniões e Palestras }\end{array}$ \\
\hline $\begin{array}{l}\text { Conhecimento tácito e } \\
\text { experiência }\end{array}$ & $\begin{array}{l}\text { Decisão da família } \\
\text { Resultados anos anteriores } \\
\text { Experiência própria } \\
\text { Base nos resultados dos vizinhos }\end{array}$ \\
\hline $\begin{array}{l}\text { v. Rede de relacionamentos e } \\
\text { participação }\end{array}$ & $\begin{array}{l}\text { Troca de informações com a vizinhança } \\
\text { Encontros com a comunidade } \\
\text { Trabalho coletivo } \\
\text { Reuniões grupais }\end{array}$ \\
\hline vi. Conhecimento de mercados & Pesquisa de mercado de produtos e insumos \\
\hline vii. Controle de despesas e receitas & $\begin{array}{l}\text { Disponibilidade de dados e informações. } \\
\text { Possibilidade de planejar com base nos dados } \\
\text { registrados (passado) }\end{array}$ \\
\hline
\end{tabular}

Fonte: Elaborado pelos autores.

Das categorias intermediárias de análise, emerge um grupo de informações que chegam aos agricultores por canais institucionais e/ou de forma estruturada, quais sejam as orientações dos técnicos relativas a produção e a gestão, as repassadas nos eventos de capacitação e aquelas reproduzidas pelas mídias de comunicação (TV, rádio, internet). Neste grupo, destaca-se em importância a informação repassada pela assistência técnica presente no estabelecimento rural. Também são valorizados os eventos de capacitação em 
que podem conhecer tecnologias e visualizar seus resultados (dias de campo, visitas a propriedades, cursos) e ferramentas para controle de despesas e receitas.

Um segundo grupo de informações se caracteriza pela forma pouco estruturada como se apresenta, tendo, porém, grande importância para os agricultores dos estabelecimentos estudados. Fazem parte deste grupo, a experiência passada, a opinião da família, a rede de relacionamentos e vizinhança e o conhecimento do mercado. Neste grupo, se constatou nos discursos dos agricultores a valorização das fontes de informação do tipo face a face (técnicos, família e vizinhos), em que comumente se construiu relações de confiança e há uma identificação socioeconômica e cultural. Outra fonte de informação valorizada foram algumas mídias de comunicação (TV e rádio), as quais podem, por ter uma audiência generalizada nas comunidades rurais, trazer temas de interesse que são debatidos pelos agricultores nos seus círculos de relacionamento.

\subsection{Determinantes da renda}

A Tabela 2 apresenta a equação estimada da renda dos estabelecimentos agropecuários que contempla os dados dos quatro anos das variáveis independentes, resultando em 923 observações. Por outro lado, ao se introduzir as variáveis relacionadas às percepções dos agricultores dos estabelecimentos agropecuários da amostra (apuradas mediante questionário aplicado em 2016) e simultaneamente os dados contábeis apurados nos quatro anos agrícolas, o número de observações usados se reduziu para 576.

O coeficiente de determinação mensura a habilidade das variáveis independentes de prever a variável dependente renda dos estabelecimentos agropecuários, sendo uma medida prática da força da relação global. Embora o coeficiente de determinação tenha se mostrado moderado $(\mathrm{R} 2=0,4229)$, sendo o teste $F$ significativo, permite aceitar a equação estimada como bem ajustada aos dados e indicar que existe a probabilidade $<.0001$ de os resultados serem obras do acaso. Isto significa que podemos justificar $42,29 \%$ da variação da renda com as quatorze variáveis independentes do modelo.

Para verificar a ocorrência de problemas de multicolinearidade, gerou-se uma matriz de correlações entre as variáveis independentes do modelo. Os resultados apontam uma associação leve e fraca a no máximo moderada (nenhum coeficiente de correlação foi maior que $+0,70$ ou menor do que $-0,70$ ), o que sugere a não ocorrência desse problema e nem a necessidade de remoção de variáveis do modelo. 
Tabela 2 - Equação estimada para o logaritmo neperiano da Renda da Operação Agrícola dos estabelecimentos agropecuários da amostra

\begin{tabular}{l|r|r|r}
\hline Parâmetro & Coeficiente & Valor $t$ & $\operatorname{Pr}>|t|$ \\
\hline Intercepto & $-22,8473$ & -0.71 & 0.4773 \\
Ano & 0,0143 & 0.90 & 0.3705 \\
UF SC & $-0,0475$ & -0.94 & 0.3460 \\
UF PR & $-0,2123$ & -3.99 & $<.0001$ \\
Logaritmo dos custos reais per capita & 0,3408 & 7.79 & $<.0001$ \\
Superfície agrícola útil & 0,0073 & 2.49 & 0.0131 \\
Unidade de trabalho homem familiar & $-0,0776$ & -3.48 & 0.0005 \\
Unidade de trabalho homem assalariada & $-0,1644$ & -2.50 & 0.0126 \\
Rendimento tabaco estufa (kg/ha) & 0,0003 & 11.49 & $<.0001$ \\
Percepcões & & & \\
- Distribuição de tempo do responsável & 0,0144 & 1.34 & 0.1822 \\
- Uso do computador para a gestão & 0,0077 & 0.91 & 0.3624 \\
- Acesso a informacões por meio de técnicos & 0,0193 & 1.00 & 0.3159 \\
- Uso do fluxo de caixa & $-0,0030$ & -0.32 & 0.7480 \\
- Uso de sistema de contabilidade eletrônica & $-0,0083$ & -0.64 & 0.5204 \\
- Disponibilidade de meios de comunicação & 0,0201 & 2.71 & 0.0069 \\
R & 0,4229 & & \\
F & & 29,36 & $<.0001$ \\
No de observacões & 923 & Usadas & 576 \\
\hline
\end{tabular}

Fonte: Elaborado pelos autores, com dados da pesquisa.

Nota: Algumas variáveis explanatórias foram suprimidas do modelo em função da elevada multicolinearidade dos regressores presentes, tais como o uso da internet para a gestão.

Além disso, as variáveis grau de instrução e idade do principal gestor foram suprimidas do modelo, dado que suas informações se fizeram incompletas.

A Tabela 3 revela a contribuição marginal de cada fator para a soma de quadrados de regressão, isto é, para a explicação das variações no logaritmo da renda dos estabelecimentos, permitindo avaliar sua importância relativa. Para facilitar a interpretação dos coeficientes das variáveis independentes, são apresentadas as porcentagens de variação da renda, dadas variações pré-estabelecidas nas variáveis explanatórias, somente para os coeficientes estatisticamente significativos. Por este motivo, por exemplo, consta apenas uma variável categórica no modelo (UF - PR), em que as variações de lucro per capita se referem à passagem da categoria de referência do Estado do Rio Grande do Sul para a categoria dos estabelecimentos do Estado do Paraná.

Tabela 3 - Variação percentual na renda dadas variações nas variáveis binárias e quantitativas relacionadas aos recursos e a percepção sobre as capacidades de uso da informação

\begin{tabular}{l|c|c}
\hline Parâmetro & Variação em X & $\begin{array}{c}\% \text { de variação } \\
\text { da renda }\end{array}$ \\
\hline UF - PR & - & $-0,19$ \\
Custos reais & $1 \%$ & 0,34 \\
Superfície agrícola útil & $1 \%$ & 0,01 \\
Unidade de trabalho familiar & $1 \%$ & $-0,07$ \\
\hline
\end{tabular}




$\begin{array}{ll}1 \% & -0,15 \\ 1 \% & 0,00 \\ 1 \% & 0,02\end{array}$

Fonte: Elaborado pelos autores com dados da pesquisa.

A partir do coeficiente estimado de cada variável binária utilizada na regressão, é possível se obter a diferença percentual entre a renda esperada de uma dada categoria e a renda da categoria base, depois de descontados os efeitos de todas as outras variáveis explanatórias incluídas na regressão. Sendo o coeficiente da variável binária expresso por b, a variação percentual da renda esperada será dado por: $100[\exp (b)-1] \%$. Para as demais variáveis, a mesma fórmula é usada para calcular o acréscimo percentual na renda obtida por cada $1 \%$ de alteração na variável independente, ou seja, a taxa de retorno do fator.

Quando a variável explanatória é binária, o efeito marginal corresponde, necessariamente, a um aumento de 1 unidade, ou seja, mudança de 0 para 1 ou da categoria de referência para a categoria em questão. Assim, o coeficiente associado à variável UF - PR indica que a renda de estabelecimento localizado no Paraná é $17 \%$ (resultado de e-0,1892-1) inferior em relação ao localizado no estado do Rio Grande do Sul, tomado como base. Observe-se, ainda, que o estabelecimento localizado em Santa Catarina não apresentou diferença significativa (valor t não significativo) de lucro per capita quando comparado ao localizado no Rio Grande do Sul e, em decorrência disto, não apareceu na Tabela 3.

Entre os resultados que revelam relação positiva com a renda, os custos reais revelaram o maior efeito marginal entre todas as variáveis independentes analisadas. Isto indica que um por cento (1\%) a mais de custo real por estabelecimento agropecuário eleva a renda em 0,34\%, em média. Assim, os resultados indicam que os agricultores, na média, ao acrescer os custos reais em $R \$ 1.000,00$ obtêm uma renda adicional de $R \$ 340,00$.

Em seguida, revelando uma relação positiva com a renda, aparece a percepção sobre a disponibilidade de meios de comunicação. Nesse caso, para o aumento de um ponto percentual na percepção positiva em relação à disponibilidade de meios de comunicação estima-se aumento de $0,03 \%$ de variação na renda do estabelecimento. Logo depois, a contribuição marginal da área agrícola explorada revela que o aumento de $1 \%$ na área eleva a renda esperada em $0,01 \%$, em média. Por último, o rendimento do tabaco estufa $(\mathrm{kg} / \mathrm{ha})$ se mostra relacionado positivamente com a renda, mas apresentando o mais baixo efeito marginal $(0,0003 \%)$. 
Os demais resultados revelaram uma relação negativa com a renda. Quanto a presença física de trabalho, para cada aumento de 1\% na unidade de trabalho assalariada e na unidade de trabalho familiar, respectivamente, haveria uma redução de 0,15\% e 0,07\% na renda do estabelecimento. Assim, independentemente se trabalho contratado ou familiar, a renda média se reduz para aumentos da presença física de trabalho no estabelecimento agropecuário.

\section{DISCUSSÃO}

O teste empírico realizado neste estudo concentrou-se na análise de estabelecimentos agropecuários que atuam em um mesmo setor, estando implícita a heterogeneidade e singularidade dos recursos, o que explica a renda observada. Assim, aqueles recursos que possuem efeito significativo e positivamente associado à renda são os recursos estratégicos. Ainda assim, é importante refletir sobre a crítica manifestada com referência aos métodos estatísticos na aplicação da VBR (HAYASHI et al., 2018): a dificuldade de se trabalhar com o pressuposto da heterogeneidade de recursos como forma de explicar em um grupo de empresas a geração e sustentação da vantagem competitiva (ARMSTRONG e SHIMIZU, 2007), e o fato da estratégia lidar com fenômenos complexos exige do pesquisador ter mindset e ferramental teórico-metodológico mais aptos a acompanhar as transformações e exigências da área da estratégia (NISSEN, 2014).

A estrutura para análise estratégica segundo a VBR proposta por Grant (1991), prevê algumas etapas que servem de referência para organizar a discussão dos resultados. Assim, na primeira etapa, o estudo permitiu identificar os recursos disponíveis do estabelecimento agropecuário e a sua avaliação, identificando fortalezas, fraquezas, ameaças e oportunidades. No cumprimento desta etapa, os dados obtidos a campo permitiram esta avaliação, ainda que limitada às percepções dos agricultores, sobre as capacidades de uso da informação, relativamente aos demais participantes do estudo.

Na segunda etapa, o enfoque da VBR para análise estratégica prevê uma avaliação do potencial de geração de renda dos recursos e capacidades. Os resultados apontados também contribuem com essa avaliação, ao identificar os efeitos dos recursos disponíveis e das percepções dos agricultores sobre a capacidade de uso da informação na renda dos estabelecimentos, além da intensidade da relação (grau de resistência) e direção (negativa ou positiva). 
A seguir, com base nas hipóteses levantadas, verifica-se a sua sustentação e as possíveis implicações:

\section{H1: quanto maior o nível de recursos físicos e financeiros, maior é a renda}

Os resultados encontrados no presente estudo sugerem que aquele que mais empregou recursos financeiros obteve mais renda.

Os resultados permitem identificar os recursos financeiros como o principal determinante da renda dos estabelecimentos pesquisados, uma vez que os custos reais apresentaram a maior contribuição marginal positiva à renda. Nesta relação, um aspecto precisa ser ressaltado sobre esses estabelecimentos agropecuários: os agricultores podem decidir alocar os recursos visando obter renda sem as restrições dos recursos financeiros. Isto ocorre porque o cultivo do tabaco é desenvolvido na forma de integração, o que possibilita ao agricultor descontar as despesas incorridas no momento da venda da safra. No mesmo sentido, a realização das inversões para compor o equipamento produtivo desses cultivos conta com financiamentos intermediados pela empresa integradora. Assim, o argumento de Penrose (1959), de que as desvantagens competitivas das empresas de menor tamanho estão ligadas às limitações de acesso ao crédito para financiar sua expansão, parecem flexibilizadas dentro de determinados limites pela empresa integradora.

Entre os recursos físicos, os resultados revelam que a área agrícola explorada é determinante da renda, mas com pequena contribuição marginal da área agrícola explorada (para cada $1 \%$ eleva a renda em apenas 0,01\%). A explicação para esse resultado se deve a pequena área agrícola explorada (14,4 ha $\pm 10,1$ ha) e a presença do tabaco como uma das principais atividades agropecuárias desses estabelecimentos. Isto porque o tabaco permite ao agricultor gerar renda em pequenas áreas, em razão do mesmo apresentar densidade econômica por área relativamente maior que as demais atividades agrícolas. Por fim, corroborando com o achado do presente artigo, diversos estudos atestam a importância das diferenças na área dos estabelecimentos agropecuários na parcela explicada da renda (DA SILVA et al., 2009; NEl et al., 2003).

Em outro sentido, os resultados revelam a relação negativa do trabalho familiar e contratado com a renda, não permitindo sustentar a hipótese $\mathrm{H} 1$. A oferta do trabalho familiar e contratado do ponto de vista qualitativo se caracteriza por ser altamente inelástica, podendo originar rendas econômicas, permitindo ao agricultor se diferenciar ao se beneficiar de um aprendizado particular (BARNEY e ARIKAN, 2001). Assim, na busca de 
explicação para a relação negativa do trabalho com a renda, se precisaria considerar também os recursos intangíveis, tais como a capacidade e a habilidade da mão-de-obra.

Em síntese, em relação a hipótese $\mathrm{H} 1$, em que pese a importância das relações apontadas para os recursos físicos, o principal resultado e determinante da desigualdade de renda se refere aos recursos financeiros, representado pelos custos reais.

\section{H2: quanto maior o nível de recursos de capital humano e tecnológicos, maior é a renda}

Os coeficientes da regressão do rendimento do tabaco permitem sustentar a hipótese $\mathrm{H} 2$, de que quanto mais se emprega recursos tecnológicos maior a renda. $A$ importância da tecnologia sobre a produtividade e renda na agricultura vêm sendo discutida desde longa data (SILVA et al.,1983; GRAZIANO DA SILVA, 1999; KAGEYAMA, 2003). São variáveis determinantes da adoção de tecnologia, dentre outras: nível de escolaridade; tamanho da propriedade; condição do produtor; área destinada à atividade; mercado; idade; sexo (gênero); renda anual; acesso à informação; comportamento de adoção no passado; comportamento de risco financeiro; experiência e infraestrutura (MENDES, 2014; MACHADO, 2008). Alves, Souza e Rocha (2012), para ressaltar a importância da tecnologia relativamente à função de produção agrícola, observaram que um aumento de $100 \%$ na renda bruta poderia ser explicado pela tecnologia (68\%), pelo trabalho (23\%) e pela terra (9\%). Assim, vários estudos corroboram esses resultados, apesar da contribuição marginal do rendimento do tabaco se revelar de pouca intensidade na presente pesquisa.

Os coeficientes da regressão da idade do agricultor e do grau de instrução não se revelaram estatisticamente significativos à renda (por isso não foram apresentados na tabela). Em termos de escolaridade, as evidências sugerem uma desigualdade consideravelmente alta entre as faixas de formação educacional analisadas. Pessoas com escolaridade de nível superior apresentaram, além de maior probabilidade de já terem usado a internet, maior frequência de uso em relação aos indivíduos com nível médio e fundamental (BARBOSA, 2017; VAN DEURSEN; VAN DIJK, 2014). Para os agricultores pesquisados, os resultados não revelaram associação entre o grau de instrução e a renda, e, nem tão pouco, entre a idade do produtor e a renda obtida pelo estabelecimento agropecuário. Em termos de grau de instrução dos agricultores, a explicação desse resultado se relaciona ao perfil dos membros das famílias, dado que, apenas $1,5 \%$ se declaram possuir ensino superior completo e $53,8 \%$ admitem possuir o ensino fundamental incompleto. 


\section{H3: quanto maior a avaliação positiva sobre as competências em lidar com a informação, maior a renda}

A avaliação positiva das percepções dos agricultores sobre as competências em lidar com a informação não se mostra preditora da renda, com exceção das percepções sobre a disponibilidade de meios de comunicação. Isso indica que os agricultores que mais referia percepção positiva sobre a disponibilidade de meios de comunicação mais obtiveram renda, sendo um resultado estatisticamente significativo com importância prática. Assim, as demais competências em lidar com a informação relacionadas à distribuição de tempo do responsável principal, do uso do computador para a gestão, do acesso a informações por meio de técnicos de ATER, do uso do fluxo de caixa e do uso de sistema de contabilidade eletrônica não se mostraram associadas à renda.

Na busca de explicação e das implicações desses resultados, alguns pontos devem ser levantados. O primeiro ponto é metodológico. As variáveis testadas refletem apenas parcialmente as competências de se lidar com a informação, uma vez que devem existir outras variáveis tão importantes às escolhidas pelo estudo. Além disso, a mente humana pode levar à interpretação ilógica ou ao discernimento impreciso da realidade (BIRKINSHAW, 2017) e, isso, precisa ser levado em conta. Assim, o agricultor avaliar a importância e declarar suas percepções sobre suas competências em lidar com a informação pode enviesar os resultados, sendo uma limitação metodológica a ser mencionada.

O segundo ponto se relaciona à pesquisa em sua face qualitativa, que demonstrou a importância manifestada pelos agricultores em relação a outros aspectos que vão além das variáveis testadas na sua face quantitativa. Essas manifestações foram agrupadas nas categorias intermediárias: canais de informação e mídias; assistência técnica; capacitação; conhecimento tácito e experiência; rede de relacionamentos e participação; conhecimento de mercados; e, controle de despesas e receitas. E sobre a importância manifestada em sua face quantitativa pergunta-se: como explicar a relativa pouca importância atribuída pelos agricultores ao uso de computador e internet para a gestão de seu estabelecimento? Antes de mais nada, se pode argumentar que o resultado revelado pelo artigo encontra suporte em várias pesquisas (VIERO; SILVEIRA, 2011; AREND et al., 2016; RITT et al., 2017) que apontaram a existência de um gap entre o uso e a sua efetiva apropriação. Os agricultores até podem ter acesso ao computador e à internet, todavia, não há compreensão da efetiva necessidade e utilidade das informações para embasar as suas decisões. Por sinal, esse parece ser o caso revelado pelo presente artigo: os números revelaram que 
94,1\% dos estabelecimentos agropecuários possuíam um ou mais computadores; e, 47,6\% dos membros dessas famílias utilizavam a internet, mas admitem fraquezas em relação ao uso desses instrumentos informacionais. Infere-se que as tecnologias de informação e comunicação não são um fim em si mesmas e que os resultados apontam para formas e meios de acesso à informação de perfil mais pessoal, portanto mais baseados no conhecimento tácito. Paradoxalmente, a par dos avanços observados nas tecnologias da informação e comunicação, compreende-se que as vantagens advindas de acessar computador e se conectar à internet tendem a se dissipar cada vez mais rápido. Assim, nos próximos anos se presume que o desafio do agricultor não mais reside nas vantagens advindas da informação e do conhecimento possuído (seu ativo intangível), mas em quão rápido ele mesmo é capaz de processar as informações e produzir conhecimento novo.

O terceiro ponto reforça e se relaciona ao papel exercido pelos recursos intangíveis, entre os quais estão a informação e o conhecimento. Os recursos intangíveis são estratégicos para o desempenho dos estabelecimentos agropecuários, mais presentes nos recursos organizacionais e humanos (CARVALHO et al., 2014, p. 515). Assim, os recursos humanos intangíveis são aqueles que possibilitam formas mais efetivas para usufruir os recursos físicos, tecnológicos e financeiros. Em que pese se reconhecer a importância dos recursos humanos intangíveis, os resultados revelados pela pesquisa, no emprego da abordagem quantitativa e de suas variáveis testadas, não são suficientes e não permitem corroborar a afirmação anterior.

A terceira etapa proposta por Grant (1991) prevê a seleção de uma estratégia para explorar os recursos, capacidades e competências únicas da empresa. No contexto dos estabelecimentos agropecuários, a identificação e análise dos recursos estratégicos não são tarefas fáceis, além de que precisam ser avaliados no contexto de cada unidade (GOHR et al., 2011). As dificuldades surgem do fato de que cada estabelecimento representa um conjunto único de portfólio de recursos (HAYASHI et al., 2018; KULL, MENA e KORSCHUN, 2016). A compreensão das relações entre os recursos e capacidades e sua rentabilidade como fonte de vantagem competitiva é determinante para o êxito da escolha de qual estratégia implementar no estabelecimento. Assim, apesar da contribuição deste artigo em revelar os recursos e as percepções dos agricultores determinantes da renda, é preciso avançar no entendimento da relação dos recursos e capacidades e a renda no âmbito individual de cada estabelecimento agropecuário. 


\section{CONCLUSÕES}

Quanto ao desenvolvimento da pesquisa, o emprego de método misto possibilitou a identificação de convergências e divergências entre os dados qualitativos e quantitativos e entre a presença física dos recursos e as percepções dos agricultores, produzindo resultados que se complementam mutuamente. Além disso, o uso do referencial teórico sobre VBR contribuiu na definição das variáveis de estudo e nas discussões realizadas, bem como na sua organização.

No que concerne as hipóteses do estudo, os resultados sugerem que quanto maior o nível de recursos (físicos, financeiros, de capital humano e tecnológicos) maior a renda dos estabelecimentos, mas não para qualquer tipo de recurso. De um lado, os custos reais se revelam estrategicamente relevantes para explicar a renda, mas, de outro lado, o grau de instrução dos agricultores e as competências percebidas em lidar com a informação não apresentaram essa mesma relação causal. De forma geral, tais achados revelam a necessidade de mais investigações com objetivo de examinar relações entre recursos, desempenho, diversificação produtiva, risco e incerteza, nos diferentes contextos que se inserem os estabelecimentos agropecuários.

Um diferencial deste artigo foi contar com uma base histórica de registros contábeis de estabelecimentos agropecuários dos três estados da Região Sul do Brasil, o que permitiu realizar as inferências sobre os recursos e capacidades percebidas no uso da informação como determinantes da renda. Outro diferencial, foi revelar a percepção dos agricultores em relação a distintos aspectos relacionados ao uso da informação, identificando fraquezas, fortalezas e grau de importância atribuído a cada um deles. Além disso, esses diferenciais estão permitindo e servindo de base a estudos sobre as múltiplas facetas da gestão de estabelecimentos agropecuários.

\section{REFERÊNCIAS}

ALVES, E.; SOUZA, G. D.; ROCHA, D. D. Lucratividade da agricultura. Revista de Política Agrícola, v. 21, p.2, p. 45-63, 2012.

ARAÚJO, L. A. et al. Agronegócios familiares do Sul do Brasil: percepções do agricultor sobre o seu ambiente. Florianópolis, SC: Epagri, 2017. 60 p. (Boletim técnico, 181). Disponível em: http://docweb.epagri.sc.gov.br/website cepa/publicacoes/Agronegocios familiares Sul Brasil.pdf Acesso em: 5 fev. 2018. 
ARAÚJO, L. A. Indicadores técnicos e econômicos para a gestão de propriedades rurais produtoras de fumo em Santa Catarina. Florianópolis: Epagri, 63 p., 2009. (Epagri. Documentos, 233).

ARAÚJO, L. A.; DE ARAUJO, A. R. M.; CATAPAN, E. As capacidades percebidas de gestão e a renda de agricultores do Sul do Brasil: um enfoque da Visão Baseada em Recursos. International Congress of Knowledge and Innovation - Ciki, [S.I.], v. 1, n. 1, sep. 2017. ISSN 2318-5376. Available at: http://proceeding.ciki.ufsc.br/index.php/ciki/article/view/284 Acesso em: 20 mar. 2018.

ARMSTRONG, C.E.; SHIMIZU, K. A review of approaches to empirical research on the resource-based view of the firm. Journal of Management, 33(6), 959-986, 2007. https://doi.org/10.1177/0149206307307645. Acesso em: 01 ago. 2019.

AREND, S.C; DEPONTI, C.M; KIST, R.B. O uso de TIC pela agricultura familiar no território do citrus: Vale do Caí-RS. Informe GEPEC. 2016 Jul;20(2):71-84. Disponível em: http://saber.unioeste.br/index.php/gepec/article/view/15638 Acesso em: 20 mar. 2018.

BALESTRIN, A.; VERSCHOORE, J. Redes de Cooperação Empresarial: Estratégias de Gestão na Nova Economia. Bookman Editora, 2016.

BARBOSA, Alexandre F. Pesquisa sobre o uso das tecnologias de informação e comunicação nos domicílios brasileiros: TIC domicílios 2016. São Paulo: Comitê Gestor da Internet no Brasil, 2017. p. 31-37. Disponível em: http://cetic.br/media/docs/publicacoes I2/TIC DOM 2016 Livro Eletronico.pdf Acesso em: 23 mar. 2018.

BARBOSA, R. de A.; MACHADO, A. G. C. Estratégias de inovação sob a perspectiva da Visão Baseada em Recursos: um estudo na Embrapa. Gestão \& Regionalidade (Online), v. 29, n. $87,2013$.

BARNEY, J. B.; ARIKAN, A. M. The resource-based view: origins and implication. In: HITT, M. A. et al. The Blackwell Handbook of Strategic Management. Oxford: Blackwell, 2001.

BINOTTO, E.; NAKAYAMA, M. K.; SIQUEIRA, E. S. A criação de conhecimento para a gestão de propriedades rurais no Brasil e na Austrália. Rev. Econ. Sociol. Rural, Brasília, v. $\quad$ 51, n. $\quad$ 4, p. $\quad$ 681-698, Dec. 2013. Available from http://www.scielo.br/scielo.php?script=sci arttext\&pid $=010320032013000400004 \&$ lng $=e n$ \&nrm=iso Acesso em: 20 Mar. 2018. http://dx.doi.org/10.1590/ S010320032013000400004

BIRKINSHAW, J.; MARK, K. 25 ferramentas de gestão: um guia sobre os conceitos mais importantes ensinados nos melhores MBA's do mundo. São Paulo: HSM, 2017. 200 p.

CARVALHO, D. M.; PRÉVOT, F.; MACHADO, J. A. D. O uso da teoria da visão baseada em recursos em propriedades rurais: uma revisão sistemática da literatura. Revista de Administração, 49(3), 506-518. 2014.

COLLIS, D. J.; MONTGOMERY, C. A. Competing on Resources: Strategy in the 1990s. Harvard Business Review, 73 (July-August), 118-128, 1995.

DA SILVA, C.; SIMIONI, F. J.; TALAMINI, E. Fatores determinantes da renda de famílias rurais do município de Painel-SC. Revista Teoria e Evidência Econômica, v. 15, n. 32, 2009. 
DESARBO, W. S.; DI BENEDETTO, C. A.; JEDIDI, K.; SONG, M. Identifying sources of heterogeneity for empirically deriving strategic types: a constrained finite-mixture structuralequation methodology. Management Science, 52(6), 909-924, 2006.

DRUCKER, Peter Ferdinand. As fronteiras da administração. Rio de Janeiro: Elsevier, 2012.

GRANT, R. M. The resource-based theory of competitive advantage: implications for strategy formulation. California management review, 33(3), 114-135, 1991.

GRAZIANO DA SILVA, J. O novo rural brasileiro. Campinas: Unicamp-IE, 1999.

GOHR, C. F. et al. Recursos estratégicos e vantagem competitiva: aplicação do modelo VRIO em uma organização do setor sucroalcooleiro. Revista Gestão Organizacional, v. 4, n. 1, p. 60, 2011.

HAYASHI P.; ITO, N.; PRADO-GIMENEZ, F.A.; PONGELUPPE, L. Entendimentos e desentendimentos da pesquisa empírica da visão baseada em recursos: uma abordagem exploratória. Estudios Gerenciales. Dec;34(149):469-80, 2018.

INSTITUTO BRASILEIRO DE GEOGRAFIA E ESTATÍSTICA. IBGE. Censo Agropecuário de 2017. Disponível em: http://www.ibge.gov.br/home/estatistica/economia/agropecuaria/ censoagro Acesso em: 1 jul. 2019.

KAGEYAMA, A.; HOFFMANN, R. Determinantes da renda e condições de vida das famílias agrícolas no Brasil. Economia. 2000 Jul;1(2):147-83.

KAGEYAMA, A. Produtividade e renda na agricultura familiar: efeitos do PRONAF-crédito. Agricultura em São Paulo. Jul; v. 50, n.2, p.1-3, 2003. Disponível e: http://www.iea.sp.gov.br/out/publicacoes/pdf/asp-2-03-1.pdf Acesso em: mar. 2019.

KAHNEMAN, D. Rápido e devagar: duas formas de pensar. Rio de Janeiro: Objetiva, 2012.

KAY, R. D.; EDWARDS, W. M; DUFFY, P. A. Gestão de Propriedades Rurais - 7. AMGH Editora; 2014.

KULL, A. J.; MENA, J. A.; KORSCHUN, D. A. Resource-based view of stakeholder marketing. Journal of Business Research, 69(12), 5553-5560, 2016. https://doi.org/10.1016/j.jbusres.2016.03.063. Acesso em:

LIRA, W. S.; CÂNDIDO G. A.; ARAÚJO, G. M. DE; BARROS, M. A. DE. A busca e o uso da informação nas organizações. 2008. Disponível em: http://www.scielo.br/pdf/pci/v13n1/v13n1a11. Acesso em: 17 jul. 2019.

MACHADO, J. G. de C. F. Adoção da tecnologia da informação na pecuária de corte. 219 f. Tese (Doutorado em Engenharia de Produção) - Universidade Federal de São Carlos, São Carlos, 2008.

MANASSERO, M., GARCÍA, E.; TORRENS, G.; RAMIS, C.; VÁZQUEZ, A.; FERRER, Y V. Teacher burnout: atributional aspects. Psichology in Spain, v. 10, n.1, p. 66-74, 2006. Disponível em: psychologyinspain.com/content/full/2006/full.asp?id=10007 Acesso em: 18 jan. 2018. 
MENDES, C. I. C.; BUAINAIN, A. M.; FASIABEM, M. C. R. Uso do computador e internet nos estabelecimentos agropecuários brasileiros. In: MASSRUHÁ, S. M. F. S. et al. Tecnologias da informação e comunicação e suas relações com a agricultura. Brasília, DF: Embrapa, 2014. p. 25-32. Disponível em: https://ainfo.cnptia. embrapa.br/digital/bitstream/item/130792/1/livro-procisur-portugues-completo-reduzido.pdf Acesso em: 23 mar. 2018.

MINTZBERG, H. Managing: desvendando o dia a dia da gestão. Tradução de Francisco Araújo da Costa. Revisão Técnica: Roberto Fachin, 2010.

MOURA, M. F; PEREIRA, N. A; RECH, I. J. Análise Quanto ao Uso de Ferramentas e Informações Gerenciais pelos Produtores de Gado de Corte. Revista Evidenciação Contábil \& Finanças. Oct 29;4(3):72-88, 2016. Disponível em: http://periodicos.ufpb .br/index.php/recfin/article/view/28869. Acesso em: 23 mar. 2018.

NAVES, M. M. L. Considerações sobre gerência de recursos informacionais. Perspectivas em Ciência da Informação, [S.I.], v. 4, n. 1, nov. 2007. ISSN 19815344. Disponível em: <http://portaldeperiodicos.eci.ufmg.br/index.php/pci/article/view/593/362>. Acesso em: 17 jul. 2019.

NEY, M. G. et al. Desigualdade de renda na agricultura: o efeito da posse da terra. Economia, v. 4, n. 1, p. 113-152, 2003.

NISSEN, M. Organization Design for Dynamic Fit: a review and a projection. Journal of Organization Design, 3(2), 30-42, 2014. https://doi. org/10.7146/jod.8196

NONAKA, I.; TAKEUCHI, H. Gestão do conhecimento. Porto Alegre: Bookman, 2008.

NONAKA, I.; TAKEUCHI, H. Criação de conhecimento na empresa: como as empresas japonesas geram a dinâmica da inovação. Rio de Janeiro: Campus, 1998. Cap.2: Conhecimento e administração, p.23-59.

PENROSE, E. T. The Theory of the Growth of the Firm. Oxford: Oxford University, 1959.

PELAEZ, V. Edith Penrose -Teoria do crescimento da firma. Revista Brasileira de Inovação, 6(2), 461-467, 2007. Available from: https://www.researchgate.net/publication/ 47690787 Edith Penrose_Teoria_do_crescimento_da_firma. Acesso em: Jul 162019.

PRAHALAD, CK.; HAMEL, Gary. The Core Competencies of the Corporation. Harvard Business Review. 1990.

RITT, Douglas et al. A apropriação de tecnologias de gestão pela agricultura familiar no Vale do Caí. Revista Jovens Pesquisadores, Santa Cruz do Sul, v. 7, n. 1, p. 118-131, jan. 2017. ISSN 2237-048X. Disponível em: https://online.unisc.br/seer/index.php/jovenspesquisadores/article/view /8871. Acesso em: 20 mar. 2018. doi: http://dx.doi.org/10.17058/rjp.v7i1.8871.

RUGMAN, A. M.; VERBEKE, A. "Edith Penrose's contribution to the resource-based view of strategic management." Strategic management jornal, 23.8: 769-780, 2002.

SERRA, F. R.; FERREIRA, M. P.; PEREIRA, M. F. Evolução da pesquisa brasileira em Resource-Based View (RBV): estudo das ENANPAD na área de estratégia entre 19972006. Revista Brasileira de Estratégia, 1(1), 39-56, 2008. 
SILVA, J. G. et al. Tecnologia e campesinato: o caso brasileiro. Revista de Economia Política, v. 3, n. 4, p. 21-56, 1983.

SILVA, A.H. Rituais corporativos como estratégia de legitimação dos valores organizacionais em empresas familiares. 2012. Disponível em: http://repositorio.ufsm.br Ihandle/1/4601 Acesso em: 26 fev. 2018.

VALLANDRO, L. F. J.; TREZ, G. Visão baseada em recursos, estratégia, estrutura e performance da firma: uma análise das lacunas e oportunidades de pesquisas existentes no campo da administração estratégica. Análise-Revista de Administração da PUCRS, 24(1), 79-81, 2015.

VAN DEURSEN, A.; VAN DIJK, J. The digital divide shifts to differences in usage. New Media \& Society, 16 (3), 507-526, 2014.

VIERO, V.C; DA SILVEIRA, A.C. Apropriação de tecnologias de informação e comunicação no meio rural brasileiro. Cadernos de Ciência \& Tecnologia. Jan 1;28(1):257-77, 201. Disponível em: http://seer.sct.embrapa.br/index.php/cct/article/view/12042 Acesso em: 20 mar. 2018.

WERNERFELT, B. A resource-based view of the firm. Strategic Management Journal, 5(2), 171-180, 1984.

ZANIN, A; OENNING, V; TRES, N; DALMUTT KRUGER, S.I, GUBIANI, C.A. Gestão das propriedades rurais do Oeste de Santa Catarina: as fragilidades da estrutura organizacional e a necessidade do uso de controles contábeis. Revista Catarinense da Ciência Contábil. 13(40), 2014. 